Tropical Journal of Pharmaceutical Research February 2017; 16 (2): 297-303

ISSN: $1596-5996$ (print); 1596-9827 (electronic)

(C) Pharmacotherapy Group, Faculty of Pharmacy, University of Benin, Benin City, 300001 Nigeria.

All rights reserved.

Available online at http://www.tjpr.org

Original Research Article

http://dx.doi.org/10.4314/tjpr.v16i2.6

\title{
Simvastatin-nicotinamide co-crystal: design, preparation and preliminary characterization
}

\author{
Iyan Sopyan ${ }^{1,2}$, Achmad Fudholi ${ }^{2 \star}$, Muchtaridi Muchtaridi ${ }^{3}$ and Ika Puspita Sari ${ }^{4}$ \\ ${ }^{1}$ Department of Pharmaceutical and Technology Formulation of University of Gadjah Mada, Yogyakarta, 55281, ${ }^{2}$ Department of \\ Pharmaceutical and Technology formulation. Faculty of Pharmacy, University of Padjadjaran, Bandung, Indonesia, \\ ${ }^{3}$ Department of Pharmaceutical Analysis and Medicinal Chemistry, Faculty of Pharmacy, University of Padjadjaran, \\ ${ }^{4}$ Department of Pharmacology and Clinical Pharmacy, Faculty Pharmacy, University of Gadjah Mada, Yogyakarta, 55281, \\ Indonesia
}

*For correspondence: Email: i.sopyan@unpad.ac.id; Tel: + 62 (022) 7796200; Fax: +62 (022)7796200

Received: 16 October 2016

Revised accepted: 23 January 2017

\begin{abstract}
Purpose: To improve the solubility of simvastatin (SV) by co-crystallization using nicotinamide (Nic) as co-crystal agent (co-former).

Methods: In silico molecular modeling of Nic counter to SV were investigated using Auto Dock 4.2. Cocrystal of Nic-SV was obtained by solvent evaporation (SE) using an equimolar ratio of Nic and SV. Cocrystal of SV-Nic was evaluated by scanning electron microscopy (SEM), saturated solubility, intrinsic dissolution, $x$-ray powder diffraction (XRPD), differential scanning calorimetric (DSC), infrared spectrophotometry (FT-IR), binary phase diagram, and for stability at $40 \mathrm{OC}$ and relative humidity (RH) $75 \%$ in one month.

Results: In silico results showed that the interaction of Nic with SV took place through hydrogen bonding as the synthon agent. The solubility and intrinsic dissolution properties of the co-crystal improved significantly compared to pure SV. Characterization of the co-crystal SV: Nic (1:1) by SEM, $X R P D, D S C, F T-I R$, and binary phase diagram indicate the formation of a new solid phase that was different from either SV or Nic. Furthermore, the cocrystal of SV: Nic remained stable for one month.

Conclusion: Co-crystallization using Nic has the potential to enhance drug solubility, intrinsic dissolution, and the stability of solution.
\end{abstract}

Keywords: Simvastatin, Co-crystal, Nicotinamide, Solubility, Dissolution

Tropical Journal of Pharmaceutical Research is indexed by Science Citation Index (SciSearch), Scopus, International Pharmaceutical Abstract, Chemical Abstracts, Embase, Index Copernicus, EBSCO, African Index Medicus, JournalSeek, Journal Citation Reports/Science Edition, Directory of Open Access Journals (DOAJ), African Journal Online, Bioline International, Open-J-Gate and Pharmacy Abstracts

\section{INTRODUCTION}

The effectiveness of drug delivery to a target organ or system in the body depends on the capability to produce suitable formulation of the drug. Deficiencies in the possessions of the solid pharmaceutical ingredient, such as solubility and bioavailability, have proved to be a major stumbling block in the successful manufacturing of medicines. The bioavailability of an oral preparation depends on its solubility which determines how quickly it is absorbed in the gastrointestinal tract and its permeability over cell membranes [1]. In pharmaceutical practice, many drugs show poor solubility in water, leading to problems with regard to dissolution and bioavailability [2]. Several drugs, including BCS class II and intravenous (IV) drugs like simvastatin (SV), have problems with solubility.

SV is an inhibitor of A (HMG-CoA) reductase; it belongs to the class of statins. Statins are the drugs of choice for the management of hypercholesterolemia due to their recognized 
efficacy and safety profile [3]. However, SV has a low solubility at about $30 \mu \mathrm{g} / \mathrm{mL}$; moreover its bioavailability is only $5 \%$ [4]. Several methods have been developed to improve the solubility of SV, such as solid dispersion [5], reduction of particle size micro emulsion [6], addition of a surfactant [7], but these methods have been somewhat insufficient. They have some shortcomings including, the high energy required of the process. Also, they involve the use of a number of matrices, and furthermore the upscaling process is complicated [4].

Co-crystallization is an emerging crystal engineering techniques used for modulating solid-state properties of the API in order to enhance pharmaceutical performance. This is possible since co-crystallization develops new solid forms with structures that are different from the constituent molecules [8]. Co-crystallization is a relatively recent technology. It has been reported to increase the solubility and dissolution profile of a water insoluble drugs [9] and is consequently considered a potential method for enhancing the bioavailability of drugs with low solubility.

Several techniques have been explored to formulate co-crystals, such as melting extrusion [10], supercritical fluids [11], forming a slurry with ultrasound [12], micronize particles [13], solid grinding [14], spray drying [15], and solvent evaporation (SE) [16]. The SE method is widely used in pharmaceutical manufacturing [17]. In the present work, we developed a simple technique of co-crystallization to improve the solubility and dissolution profile of SV using Nic as coformer.

\section{EXPERIMENTAL}

Simvastatin was obtained from Teva (Belgium) with purity > $99 \%$ ). Methanol pro analysis was obtained from Merck (Germany), and nicotinamide pro analysis was obtained from Sigma-Aldrich (Germany). Furthermore, potassium dihydrogen phosphate pro analysis was sourced from Merck (Germany).

\section{In silico molecular docking simulation}

The 3D-structures of SV and Nic were built using LigandScout 4.1 and energy minimization by $\mathrm{MM}+$. Moreover, the compound conformations were produced using the Discovery Studio 2.5 with CATALYST finest conformation module. Chemistry at harvard macromoleculer mechanic (CHARMM forced field was applied for energy optimization. Molecular Docking simulations of the molecules were done as follow Ikram et al
[18]. The AutoDockTools (ADT) script was directed to convert the ligand protein data bank (PDB) to the protein bank charge partial (PBQ) format. Also, Gasteiger charges were added and polar hydrogen was inspected.

\section{Co-crystal synthesis by solvent evaporation}

SV and Nic, accurately weighed in the molar ratio of $1: 1$ were mixed and diluted assisted by methanol, shaken for $10 \mathrm{~min}$, and later stored in a water bath at $30{ }^{\circ} \mathrm{C}$ for $24 \mathrm{~h}$ for drying. The cocrystal thus obtained was stored in room temperature.

\section{Scanning electron microscopy (SEM)}

The external morphology of the samples (cocrystals of SV-Nic) was examined using SEM (JSM6360A, JEOL, USA). Samples were placed on a double-handled sticky tape sputtered by platinum. Scanning photos were reserved at an accelerating step of $5 \mathrm{kV}$.

\section{Saturated solubility studies}

Dried co-crystal equivalently to SV $100 \mathrm{mg}$ of reconstituted with $50 \mathrm{~mL}$ of distilled water in a vial. It was shaken for $24 \mathrm{~h}$ using an agitator shaker, the concentration of dissolved SV was determined using validated Uv-Vis spectrophotometry (Analytical Zena, Germany). The procedure was repeated for pure SV, and physical mixture of SV: Nic (1:1).

\section{Intrinsic dissolution studies}

The intrinsic release behaviors of the SV and its co-crystals were determined using a dissolution tester (USP type two: paddle apparatus). A cocrystal equal to $250 \mathrm{mg}$ SV in powders was compressed into pellet forms with hardness 30 $\mathrm{KgF}$, then put into a $900 \mathrm{~mL}$ simulated intestinal fluid (less enzyme) pH 4.5 stirred at $100 \mathrm{rpm}$. Sampling $(5 \mathrm{~mL})$ was done at 10 min interval up to $60 \mathrm{~min}$ a fresh $5 \mathrm{~mL}$ SIF solution was added into the system to replenish withdrawn samples after each sampling. Each sample withdrawn was filtered through a syringe filter of $0.45 \mu \mathrm{m}$ pore size, and its UV absorbance was measured at $240 \mathrm{~nm}$ (spectrophotometer, Analytical Zena, Germany). SV concentration was calculated using a validated pre-constructed calibration curve. The same procedure was repeated for pure SV dissolution procedure.

Fourier transforms infra-red (FT-IR) spectrophotometry studies 
Powdered samples were mixed with potassium bromide crystal at the molar ratio (1: 10), and then compressed at a pressure of 20 psi. The spectra were analyzed over a range of wavenumbers 4000-400 $\mathrm{cm}^{-1}$, using FT-IR (Specord 200, Germany).

\section{X-ray powder diffraction(XPD) analysis}

The x-ray powder diffractometer (X Philips Analytical PW1710, Germany) arrays were collected using $\mathrm{Cu} \mathrm{Ka}$ radiation $(\mathrm{I}=1.54 \AA$ 趹, a duct stage of $40 \mathrm{kV}$ and a duct current of $40 \mathrm{~mA}$. Records were collected from $2 \Theta$ angle $5^{\circ}-48^{\circ}$ at a constant image rate of $4 \% \mathrm{~min}$.

\section{Thermal analysis}

Thermal analysis of the samples was carried out on a DSC/TGA apparatus (Linseis PTA ST 1600, Germany) which was adjusted for heat and cell constants using indium. Samples (2 - $3 \mathrm{mg})$ crumpled in the aluminium pan were examined from $50-300{ }^{\circ} \mathrm{C}$ at a heating rate of $10{ }^{\circ} \mathrm{C} / \mathrm{min}$. Samples were constantly purged with nitrogen at $50 \mathrm{ml} / \mathrm{min}$

\section{Preparation of binary phase diagram}

The binary phase diagram is made by making the mixture with SV: Nic with mole fraction comparison among SV-Nic (0:10) until (10:0), then each mixture was measured at its melting point, afterward, it was plotted in the charts form.

\section{Stability studies}

Profile of co-crystal stability SV: Nic (1:1) was examined thru observing a melting point of the co-crystal that were kept in a storage condition $40{ }^{\circ} \mathrm{C}$ and $\mathrm{RH} 75 \%$ for one month.

\section{RESULTS}

In silico studies (Figure 1) revealed that the lowest Gibbs-free energy of molecule conformation was $-2.5 \mathrm{kcal} /$ mole and distance of the bonding was $2.168 \AA$.

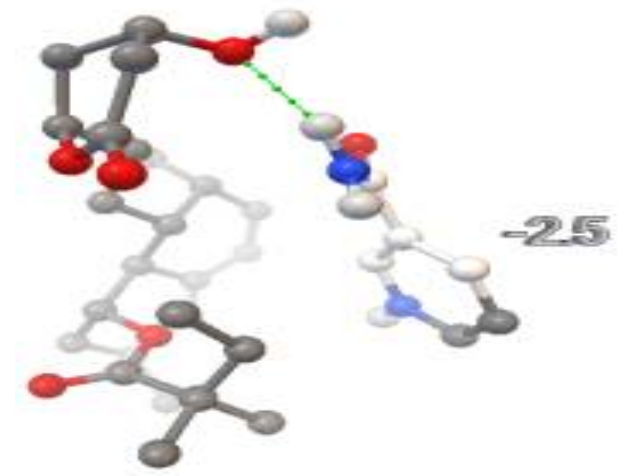

Figure 1: In silico molecular interaction model of SV and $\mathrm{Nic}$

\section{SEM of co-crystal of SV-Nic (1:1)}

SEM (Figure 2) show particle size and surface morphology of pure SV and co-crystal. Co-crystal of SV: Nic (1:1) presented a more compact structure with a higher density.

\section{Saturation solubility}

Result of the saturated solubility of co-crystal show a threefold increase compared to SV and the PM. Cocrystal SV-Nic 1:1 reached $30 \mu \mathrm{g} / \mathrm{mL}$ and SV was $9 \mu \mathrm{g} / \mathrm{mL}$.

\section{Intrinsic dissolution}

The dissolution value of the co-crystal SV-Nic (1:1) shows an increase by approximately four times (400\%) compared to the value of pure SV over a $60 \mathrm{~min}$ period (Figure 3)

\section{FT-IR spectra}

The spectrum overlay of pure SV, Nic and cocrystal SV-Nic (1:1) show the widening of the cocrystal absorption at wavenumber 3600 - 3200 $\mathrm{cm}^{-1}$ (Figure 5).

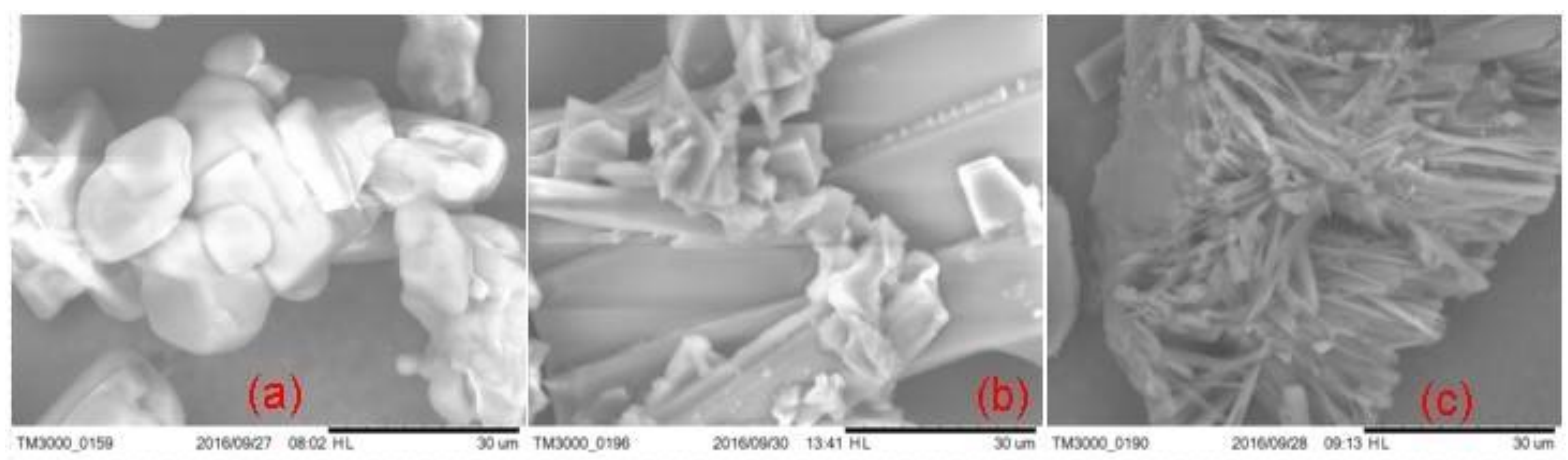

Figure 2: SEM of Nic (a), SV (b), Co-crystal SV-Nic (c) 


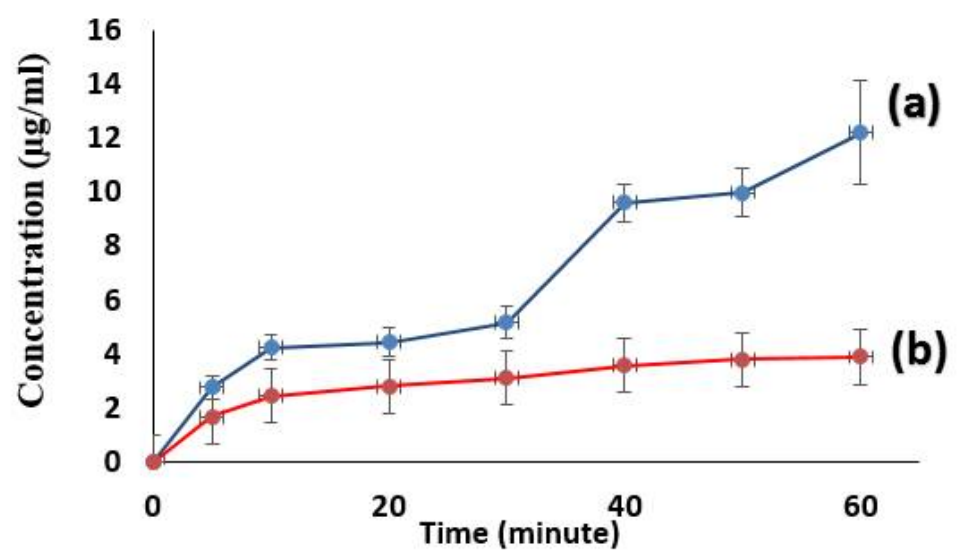

Figure 3: Intrinsic dissolution profile of co-crystal SV-Nic 1:1 (a) and pure SV (b) $(n=6)$

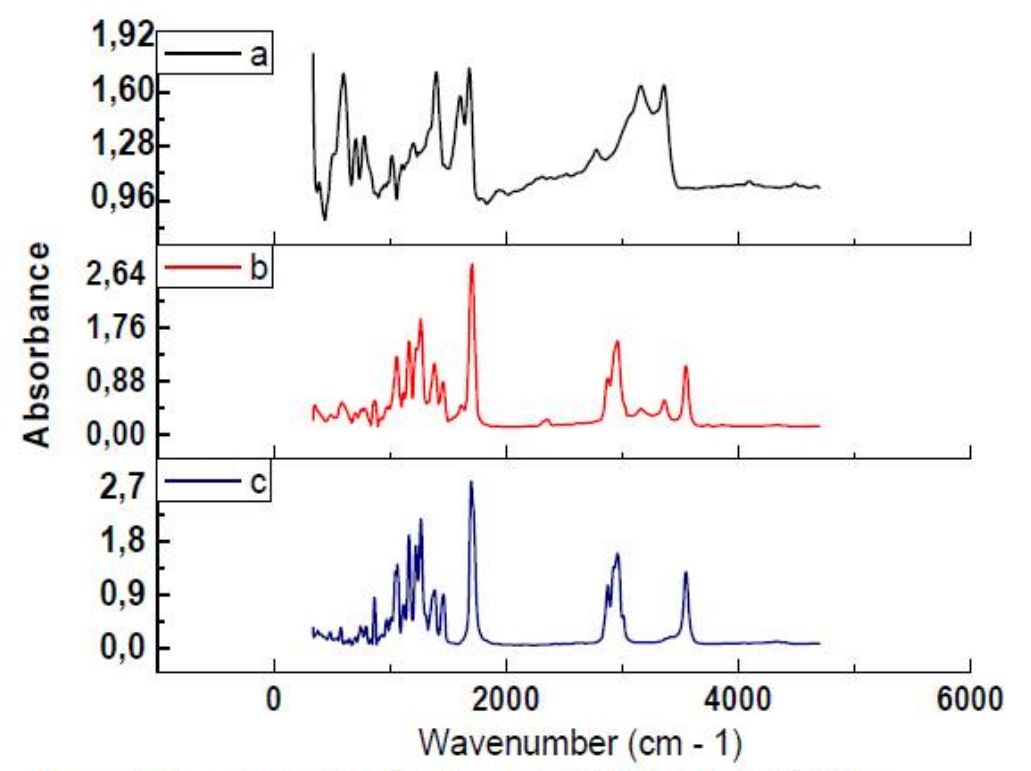

Figure 4: Spectrum of Nic (a), Co-crystal SV-Nic (b) and SV (c)

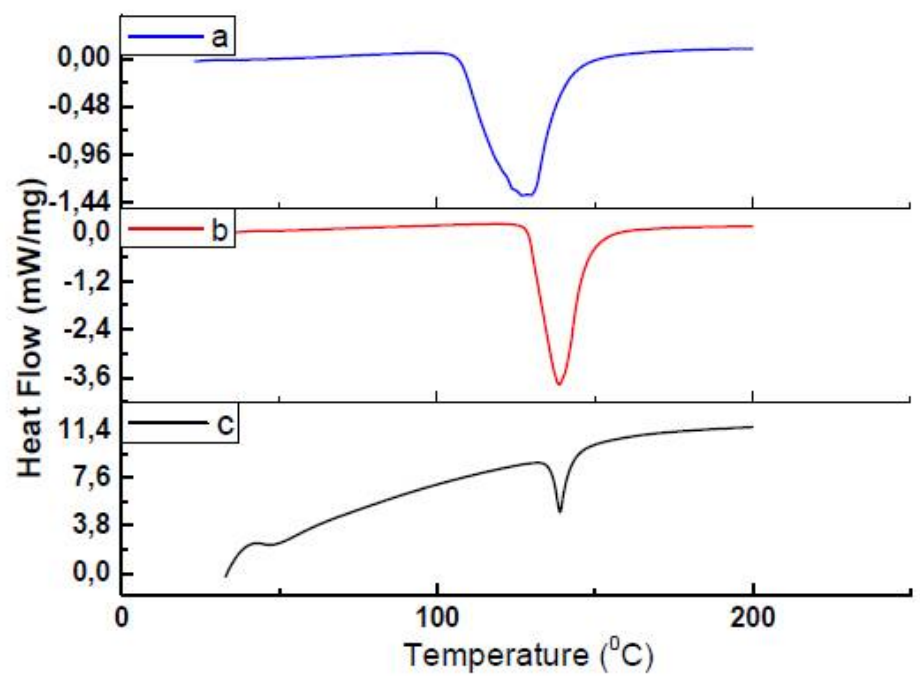

Figure 5: DSC thermogram of co-crystal SV: Nic 1:1 (a), Nic (b), and SV (c)

\section{Thermal properties}

The thermogram (Figure 5) reveal that the melting point (endotherm phase) of co-crystal
SV-Nic $\left(105.7^{\circ} \mathrm{C}\right)<$ pure SV $\left(135.8^{\circ} \mathrm{C}\right)$. The enthalpy of SV (-74.4 Joule/g) > co-crystal SVNic 1:1 (-80.68 Joule/g). 


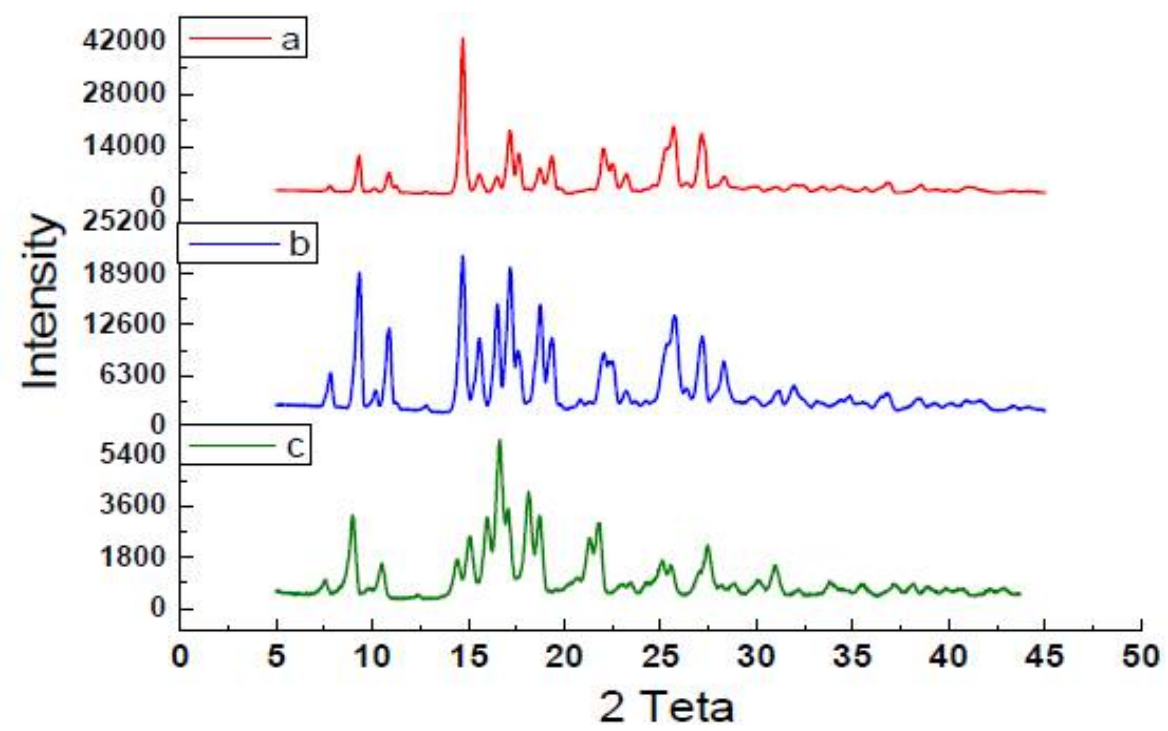

Figure 6: Diffractogram of SV (a), co-crystal SV: Nic 1:1 (b), and PM of SV: Nic (c)

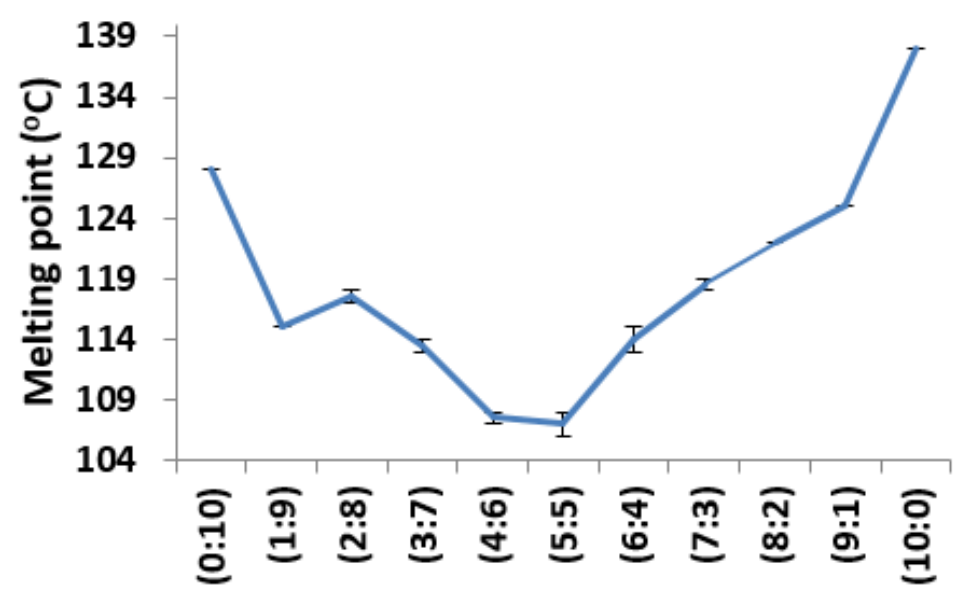

Mol fraction (Nic: SV)

Figure 7: Binary phase diagram of (Nic: SV)

XPD

The XRPD verify the formation of co-crystal of SV: Nic (1:1) as compared to SV and its PM. The diffractogram show distinct peaks and intensity at $17-20^{\circ}$, and $20-30^{\circ}$. (Figure 6).

\section{Binary phase diagram}

The binary phase diagram (Figure 7) showed distinct eutectics points at the mole fractions of (4:6), (5:5) and (6:4). At (5:5) point, the melting point reached the lowest value.

\section{Stability}

The thermograms (Figure 8) showed no change in melting point at $105.5{ }^{\circ} \mathrm{C}$ Co-crystal for 1 month in storage conditions of $40^{\circ} \mathrm{C}$ and $\mathrm{RH} 75$ $\%$

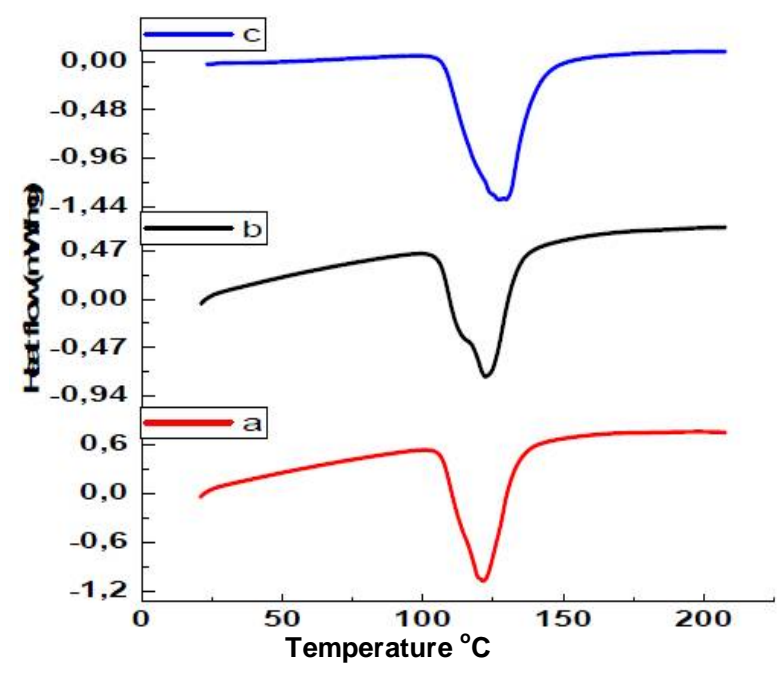

Figure 8: Thermogram overlay of co-crystal SV:Nic $(1: 1)$ for 10 day (a), 20 day (b), and 30 day (c) 


\section{DISCUSSION}

In silico studies by molecular modeling have been performed as a simple tool to study the hydrogen bonding of the SV and Nic [19]. The negative value of Gibbs-free energy obtained through in silico simulation modeling indicates that the interaction of SV and Nic occurred spontaneously. The interaction of SV and Nic takes place through hydrogen bonds that have been categorized as the hetero-synthon for this co-crystal. SV and Nic shows very close bonding and also allows the existence of the hydrogen bonds. SE method was used because it yielded co-crystals of a high degree of purity using cocrystal constituents in an equimolar ratio, and the solvent also served as the catalyst [1].

SEM showed that the co-crystals had a more compact structure with higher density. This was due to the hydrogen bonding interaction of the $\mathrm{SV}$ and Nic in co-crystal form. Previous studies have also indicated that a hydrogen bonding has an important part in the molecular interaction of co-crystallization [20]. Nic was chosen as the coformer for considerations such as polarity, availability of synthon and stability. The increase in the solubility and dissolution rate was caused by the intensified affinity of the solvent to SV. It was initiated by the existence of the co-former, apart from the decrease in the energy of the crystal lattice via co-crystal formation [12].

FT-IR is a general spectroscopic approach that is very effective to determine co-crystal, since the formation of a co-crystal involves hydrogen bonds [21]. The spectrum has shown a broadening peak as a result of the intermolecular hydrogen bonding, and this is especially applicable to the peak at $3.545 \mathrm{~cm}^{-1}$. It is specifically related to intermolecular hydrogen bonding formation.

A decrease in the melting point and heat content of the co-crystal will directly correlate to increased solubility of the API in the co-crystal. The melting point of the co-crystal would fall between the melting points of the API and its coformer [22].

$\mathrm{X}$-ray powder diffraction is a specific technique to confirm whether the new solid state and the pharmaceutical co-crystal are prone to forming isostructural phases [23]. The intensity of the emissions from the co-crystal showed a decreasing tendency in intensity due to changes in crystal habits [24]. Consequently, a number of distinct co-crystal peaks were obtained as compared to the PM, thus indicating a different structure.
The binary phase diagram exhibited three lowest points forming a $\mathrm{W}$ pattern. This may be interpreted as the pattern of co-crystal habits [25]. DSC was used to observe the stability of the co-crystal, as studying the temperature and relative humidity is the most established method to assess stability in solid state [26]. The melting point and XRPD pattern on days 10, 20 and 30 respectively showed constant values. It was confirmed that the co-crystal remained stable for a term of one month under storage conditions of $40{ }^{\circ} \mathrm{C}$ and $\mathrm{RH} 75 \%$.

\section{CONCLUSION}

Preparation of the co-crystal of SV with co-former Nic (1:1) has been successfully carried out using solvent evaporation method. Evaluation of the saturated solubility and intrinsic dissolution of SV: Nic (1:1) co-crystal indicate that the solubility rate and release behaviour of SV-Nic co-crystal (1: 1) is significantly than the pure SV.

\section{DECLARATIONS}

\section{Acknowledgement}

The authors acknowledge PT Gracia pharmindo for providing some materials for the study.

\section{Conflict of Interest}

No conflict of interest associated with this work.

\section{Contribution of Authors}

The authors declare that this work was done by the authors named in this article and all liabilities pertaining to claims relating to the content of this article will be borne by them.

\section{Open Access}

This is an Open Access article that uses a funding model which does not charge readers or their institutions for access and distributed under the terms of the Creative Commons Attribution License (http://creativecommons.org/licenses/by 14.0) and the Budapest Open Access Initiative (http://www.budapestopenaccessinitiative.org/rea d), which permit unrestricted use, distribution, and reproduction in any medium, provided the original work is properly credited.

\section{REFERENCES}

1. Vasconcelos $T$, Sarmento B, Costa P. Solid dispersions as strategy to improve oral bioavailability of poor water 
soluble drugs. Drug Discov. Today. 2007; 12: 10681075

2. Hiendrawan $S$, Veriansyah $B$, Tjandrawinata $R R$. Micronization of fenofibrate by rapid expansion of supercritical solution. J. Ind. Eng. Chem. 2014; 20: 54 60

3. Schachter M. Chemical, pharmacokinetic and pharmacodynamic properties of statins: an update. Fundam. Clin. Pharmacol. 2005; 19: 117-125

4. Murtaza G, Solubility enhancement of simvastatin: a review, Acta Pol. Pharm. 2012; 69: 581-90

5. Yang $G$, Zhao J, Feng $N$, Zhang $Y$, Liu $Y$, Dang B, Improved dissolution and bioavailability of silymarin delivered by a solid dispersion prepared using supercritical fluids. Asian J. Pharm. Sci. 2015; 10: 194202

6. Margulis-Goshen K, Magdassi S. Formation of simvastatin nanoparticles from microemulsion. Nanomedicine Nanotechnol. Biol. Med. 2009; 5: 274 281

7. Sander JR, Bučar DK, Henry RF, Zhang GG, MacGillivray LR. Pharmaceutical Nano-Co-crystals: Sonochemical Synthesis by Solvent Selection and Use of a Surfactant. Angew. Chem. 2010; 122: 7442-7446

8. Blagden N, de Matas M, Gavan PT, York P. Crystal engineering of active pharmaceutical ingredients to improve solubility and dissolution rates. Adv. Drug Deliv. Rev. 2007; 59: 617-630.

9. Good DJ, Rodríguez-Hornedo N. Solubility Advantage of Pharmaceutical Co-crystals. Cryst. Growth Des. 2009; 9: 2252-2264

10. Fule R, Amin P. Development and evaluation of lafutidine solid dispersion via hot melt extrusion: Investigating drug-polymer miscibility with advanced characterisation. Asian J. Pharm. Sci. 2014; 9: 92-106

11. Fattahi A, Karimi-Sabet J, Keshavarz A, Golzary A, Rafiee-Tehrani M, Dorkoosh FA. Preparation and characterization of simvastatin nanoparticles using rapid expansion of supercritical solution (RESS) with trifluoromethane. J. Supercrit. Fluids, 2016; 107: 469478

12. Dhumal RS, Biradar SV, Paradkar AR, York P. Particle engineering using sonocrystallization: salbutamol sulphate for pulmonary delivery. Int. J. Pharm. 2009; 368: 129-137

13. Takata N, Shiraki K, Takano R, Hayashi Y, Terada K. Cocrystal screening of stanolone and mestanolone using slurry crystallization. Cryst. Growth Des. 2008; 8: 30323037

14. Junyaprasert VB, Morakul B. Nanocrystals for enhancement of oral bioavailability of poorly watersoluble drugs. Asian J. Pharm. Sci. 2015; 10: 13-23
15. Muehlenfeld $C$, Kann B, Windbergs $M$, Thommes $M$. Solid Dispersions Prepared by Continuous Cogrinding in an Air Jet Mill. J. Pharm. Sci. 2013; 102: 4132-4139

16. Alhalaweh A, Kaialy W, Buckton G, Gill H, Nokhodchi A, Velaga SP. Theophylline Co-crystals Prepared by Spray Drying: Physicochemical Properties and Aerosolization Performance. AAPS PharmSciTech. 2013; 14: 265-276

17. Dengale SJ, Ranjan OP, Hussen SS, Krishna BSM, Musmade PB, Gautham Shenoy G, Bhat K. Preparation and characterization of co-amorphous RitonavirIndomethacin systems by solvent evaporation technique: Improved dissolution behavior and physical stability without evidence of intermolecular interactions. Eur. J. Pharm. Sci. 2014; 62: 57-64

18. Ikram NKK, Durrant JD, Zalaludin AS, Purwitasari N, Mohamed N, Rahim ASA, A virtual screening aroach for identifying plants with anti H5N1 neuraminidase activity. J Chem Inf Model. 2015; 55: 308-316.

19. Etter MC. Hydrogen bonds as design elements in organic chemistry. J. Phys. Chem. 1991; 95: 4601-10

20. Childs SL, Chyall LJ, Dunlap JT, Smolenskaya VN, Stahly BC, Stahly GP. Crystal engineering approach to forming Co-crystals of amine hydrochlorides with organic acids. Molecular complexes of fluoxetine hydrochloride with benzoic, succinic, and fumaric acids. J. Am. Chem. Soc. 2004; 126: 13335-13342

21. Aakeröy CB, Fasulo $M$, Schultheiss $N$, Desper J, Moore C. Structural competition between hydrogen bonds and halogen bonds. J. Am. Chem. Soc. 2007; 129: 1377213773

22. Aakeröy CB. Crystal Engineering: Strategies and Architectures. Acta Crystallogr. B. 1997; 53: 569-586

23. Miroshnyk I, Mirza S, Sandler N. Pharmaceutical cocrystals-an opportunity for drug product enhancement. Expert Opin. Drug Deliv. 2009; 6: 333-341

24. Engers $D$, Teng J, Jimenez-Novoa J, Gent $P$, Hossack $S$, Campbell C, Thomson J, Ivanisevic I, Templeton A, Byrn S, et al, A solid-state approach to enable early development compounds: selection and animal bioavailability studies of an itraconazole amorphous solid dispersion, J. Pharm. Sci., 2010; 99: 3901-3922.

25. Hiendrawan S, Veriansyah E, Widjojokusumo, Soewandhi SN, Wikarsa S, Tjandrawinata RR. Physicochemical and mechanical properties of paracetamol Co-crystal with 5-nitroisophthalic acid, Int. J. Pharm. 2016; 497: 106-113.

26. Reutzel S, Edens M, Newman AW. Physical characterization of hygroscopicity in pharmaceutical solids, Polymorph. Pharm. Ind. 2006: 235-258. 